\title{
The Relationship of Employment to Self-Perception and Well-Being in Women: A Cognitive Analysis
}

\author{
Paula R. Pietromonaco, ${ }^{1}$ Jean Manis, and Hazel Markus \\ Center for Continuing Education of Women, \\ University of Michigan
}

We investigated the relationship of employment to self-perception and wellbeing in women who held two different cognitive orientations toward paid work (career oriented and not career oriented) and who also varied in the degree to which their current employment status realized their view of paid work. The data were taken from a 1977 survey of a large sample of women and included responses to questions about self-esteem, life satisfaction, and self-perception. The results indicated that career-oriented women who were employed full time were happier with themselves and their lives than those employed part time or not employed. In contrast, for women who were not career oriented, being employed was not associated with greater self-esteem or well-being. In addition, career-oriented women who were employed were the most likely to emphasize job-related characteristics in their selfdescriptions. These findings suggest that the psychological benefits of employment that have been identified repeatedly in previous research are likely to be accrued only by women who regard paid work as a meaningful selffulfilling activity.

Paid employment has become increasingly significant in the lives of women. The number of employed women rose by nearly 12 million from 1970 to 1979 , an increase of $47 \%$. Approximately $51 \%$ of all women now work outside of the home, and for women between the ages of 20 to 54 the figure is $65 \%$ (U.S. Department of Labor, 1980).

This national trend has stimulated interest in the impact of employment on women. A recent New York Times poll (Dowd, 1983) finds

${ }^{1}$ To whom reprint requests should be addressed at the Department of Psychology, University of Massachusetts, Amherst, Massachusetts 01003. 
that many women are happy to be employed. In fact, when asked about the most enjoyable aspects of being a woman, motherhood and career were mentioned equally often. This stands in striking contrast to earlier results. In 1970, in response to the same question, six times as many women listed being a mother as having a career or job (Gurin, 1984).

A number of studies suggest that working outside the home is uniformly beneficial for both the psychological and physical health of women. Feld (1963) found that employed mothers viewed themselves more positively, and experienced fewer psychosomatic and physical symptoms than mothers who did not work for pay. Furthermore, employed women, in contrast to women who were not employed, appeared to have better mental health (Kessler \& McRae, 1982) and greater satisfaction with their lives (Burke \& Weir, 1976; Ferree, 1976). Employed middle-aged women (40-59 years old) also were characterized by greater psychological well-being, higher self-esteem, and better physical health, relative to their unemployed counterparts (Coleman \& Antonucci, 1983).

At the same time, other researchers have argued that women working outside the home are not happier or most satisfied than women who are not working (Campbell, Converse, \& Rogers, 1976; Wright, 1978). And, a recent review (Warr \& Parry, 1982) of the effect of paid work on well-being concludes that employment in itself bears little relationship to women's reported happiness or distress, but that how employment interacts with a number of other variables may be critical in determining the nature of this relationship.

A variety of environmental and social factors have been proposed as mediators of the relationship between employment and well-being. Among the factors that control whether paid work leads to greater well-being are occupational involvement and quality of work relationships (Warr \& Parry, 1982), and how much responsibility a woman's partner accepts for household and child care tasks (Kessler \& McRae, 1982). Equally important to the relationship between paid work and well-being is the meaning of work in one's life (Dubin, 1956), or one's commitment to the work role (cf. Bielby $\&$ Bielby, 1984). The thoughts, attitudes, and feelings that individuals have about their work, or their cognitive perspective on work, lend structure to their perceptions and interpretations of their work life (Manis \& Markus, 1980; Markus, 1980) and may partly determine the nature of the work experience. Thus, to understand the consequences of employment for wellbeing, individuals' perceptions of the value or significance of paid work in their lives need to be taken into account. Is employment construed as a job fulfilling financial needs, or as one's life work and career?

This study begins to examine how women's thoughts about their work role influence the effect of paid employment on their lives. The paid work 
role can take on a variety of meanings (cf. Markus, 1980). Many women see their paid work role as a central part of themselves, as their career, or as the continuation and fulfillment of their longstanding goals. For these women, employment may play a primary role in defining themselves and in providing meaning in their lives. For other women, employment may be thought of as just a job-a necessary part of their lives that contributes only negligibly, if at all, to their identities. These women may find other aspects of their lives, such as their relationships with their partners or children, more important for their self-definitions.

Whether employment is related to greater happiness and satisfaction may depend largely on the particular view of paid work that an individual holds. For some women, employment is regarded as a career and long-term goal, and is likely to be a central part of their view of themselves and their lives. For others, employment is not considered a career or life goal, and is not likely to be significant in their perceptions of themselves or their lives.

In the current study, we hypothesized that employment is most likely to facilitate psychological well-being when it is viewed not merely as a job, but as a valuable life work and/or career. To explore this idea, we examined the relationship of employment to self-perception and well-being for women who held two distinctly different views of the role of paid work in their lives. Moreover, we expected that the relationship of employment to selfperception and well-being may well be contingent upon whether one's view of paid work is being realized or expressed by one's current employment situation. For example, only some of the women who work full time are likely to regard it as an important self-fulfilling activity. Full time employment is likely to correspond with the work views of career-oriented women, but not with those of women who are not career oriented. To assess the match between cognitive perspectives on paid work and current employment situations, we looked at three levels of employment - not employed, employed part time, and employed full time - for women with different views of the role of paid work in their lives.

\section{METHOD}

\section{Subjects}

The data analyzed here were taken from a survey conducted in 1977 by the Center for Continuing Education of Women (CEW) at the University of Michigan. A 10-page questionnaire was mailed to 3200 former CEW participants and was returned by approximately $60 \%$ of the women who actu- 
ally received it. Of the 1143 women who responded, we selected 853 women who had complete data on the independent and control variables. The age range of the women in the sample used here was 25-59 years, with a mean age of 39.11 years. In general, the CEW respondents have higher educational levels and family incomes than would be expected for women in the same age ranges in a more representative national sample. For a detailed comparison of the CEW respondents with a representative national sample by age, see Favor (1979).

\section{Measures}

Career Orientation. The meaning of the paid work role for each individual was determined by responses to the question, "Would you describe yourself as having long-range employment or career goals - that is, do you think in terms of not just 'a job,' but of working the rest of your life in a specific field or type of work and developing and using skills necessary for that field?" If individuals responded, "Yes, I do think of myself as having or planning a career," they were considered to be career oriented and their careers were assumed to be salient in their perceptions of themselves. For individuals responding, "No, I do not think of myself as having or planning a career," it was assumed that the paid work role was not of particular importance to their view of self. The majority of women in our sample $(87 \%$ ) regarded themselves as career oriented, and only a small proportion $(13 \%)$ perceived themselves as not having or planning a career.

To determine the attitudes underlying each type of career perspective, we also examined responses to a set of statements that measured career emphasis, in contrast to an emphasis on family. The statements were as follows: "For me, it is (would be) more important to help my husband in his career than to have a career of my own," "The rewards and satisfaction of raising a family are more important to me than anything else," "Seriously pursuing a career involves costs in other areas of my life that I am not willing to accept," "I can't picture having a fully satisfying life without a career of my own," "I would not take a job that would interfere with the things I like to do with my family," and "I can't imagine having a fully satisfying life without having children." These statements were rated on a 5-point scale ranging from agree to disagree. The responses were coded so that higher ratings indicated greater emphasis on one's career, or less emphasis on one's personal or family life. A mean score was computed from the six items (Cronbach's alpha $=.74$ ).

Employment Status. Three levels of employment status were observed: not employed, employed part time, and employed full time. Of the women 
in the sample, $24 \%$ were not employed, $31 \%$ were employed part time and $45 \%$ were employed full time.

Self-Esteem. The self-esteem index (adapted from the Rosenberg SelfEsteem Scale, 1965) consisted of the following three positive and three negative statements: "I am able to do things as well as most other people," "I feel that I do not have much to be proud of," "Sometimes, I feel that I can't do anything right," and "I feel that my life is not very useful." Each item was rated on a 5-point scale ranging from disagree to agree. Mean self-esteem scores were computed from these items such that higher scores reflect a more positive view of self (Cronbach's alpha $=.71$ ).

Life Satisfaction. As a general indicator of life satisfaction and wellbeing, we examined respondents' ratings of the statement "I think of my life today as interesting and satisfying." Responses were made on the same scale as for self-esteem.

Self-Descriptions. We also explored whether employment status held any relationship to the way that women described themselves on each of 11 adjectives. Some of the adjectives were particularly relevant to behavior in paid work situations (competitive occupationally, independent, intellectual, resourceful, successful occupationallly, and successful academically), while others were less directly relevant to behavior in paid work situations (conventional, creative, nervous, successful socially, and attractive). Adjectives were rated on a 5-point scale ranging from very self-descriptive to does not apply to me.

Control Variables. The analyses controlled for age, educational attainment, and marital status, which were likely to be correlated with employment status and life satisfaction. Educational attainment was coded as 1 , no college $(n=12) ; 2$, some college $(n=105) ; 3$, bachelor's degree $(n=133)$; 4 , some graduate work and no further degree $(n=139) ; 5$, master's degree $(n=294) ; 6$, some graduate work in addition to a master's degree $(n=86)$; and 7, Ph.D. or professional (e.g., J.D., M.D.) degree $(n=84)$. Respondents were defined as not married (coded 1 ) if they were single, divorced, separated, or widowed, or as married (coded 2) if they were married or living with a partner.

\section{RESULTS}

\section{Career Emphasis}

To verify that our career-oriented and not career-oriented classifications reflected different cognitive perspectives, we examined individuals' beliefs about the relative importance of their career or family life. The mean 
career emphasis scores were analyzed by employment status using an analysis of covariance with age, education, and marital status as the covariates. As anticipated, career-oriented women emphasized their careers to a markedly greater degree than women who were not career oriented, or, conversely, career-oriented women placed less stress on their family life [adjusted means were 3.33 and 2.30 , for career oriented and not career oriented, respectively; $F(1,833)=97.17, p<.00001]$. Thus, women who thought of themselves as having or planning a career were more likely to agree that "I can't picture having a fully satisfying life without a career of my own" and to disagree with a number of statements that emphasized their family life, such as "I can't imagine having a fully satisfying life without having children" or "I would not take a job that would interfere with the things I like to do with my family." Women who were career oriented, then, had very different attitudes toward paid work and family roles than women who were not career oriented.

\section{Self-Esteem}

Does employment enhance self-esteem? Employment was associated with higher self-esteem, but only for women who thought of the paid work role as a significant and meaningful part of their lives. Figure 1 presents the mean self-esteem scores adjusted for the covariates by employment status and career orientation. Women who viewed themselves as having or planning a career showed higher self-esteem as their employment status increased from not employed to employed full time. For women who were not career oriented, however, full-time employment was not related to their feelings about themselves.

Because nearly seven times as many women in our sample were career oriented as were not career oriented, the analyses were performed separately for respondents within each type of career orientation to avoid inappropriate comparisons between cells with very large and very small sample sizes. For each career-orientation group, an analysis of covariance, in which age, educational attainment, and marital status were the covariates, was performed on the self-esteem scores by employment status (not employed, employed part time, or employed full time).

For career-oriented women, self-esteem was associated significantly with employment status $[F(2,725)=8.87, p<.0002$ (adjusted means, 4.27, $4.32,4.48$, for not employed, employed part time, and employed full time, respectively]. Scheffé comparisons indicated that women employed full time had higher self-esteem than women employed part time $(p<.002)$ and than women who were not employed $(p<.0002)$. The self-esteem scores of career- 

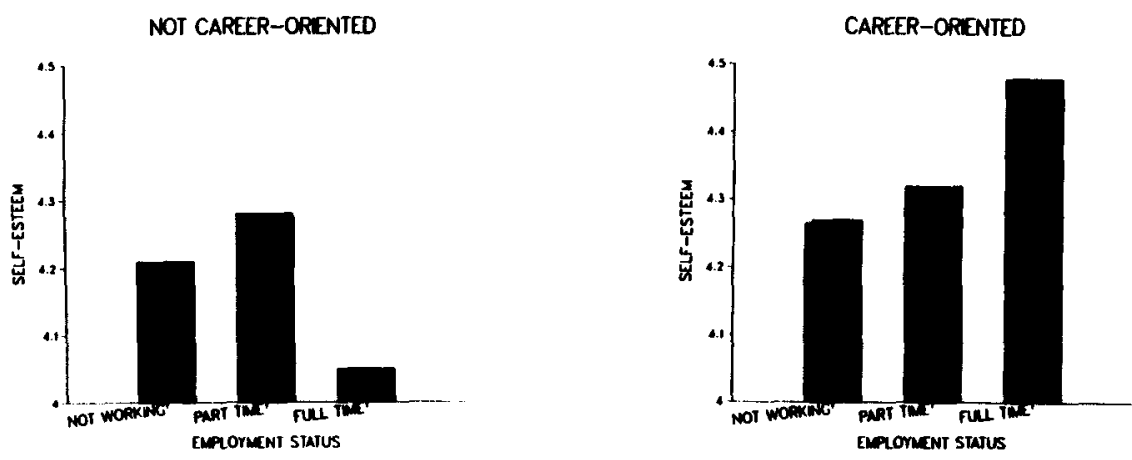

Fig. 1. Mean adjusted self-esteem scores by career orientation and employment status.

oriented women who were employed part time, in contrast to those not employed, did not differ reliably, although self-esteem scores were slightly higher for women employed part time.

For women who did not think of themselves as having a career, employment was not related significantly to self-esteem $[F(2,99)=1.07$ (adjusted means, 4.21, 4.28, 4.03, for not employed, employed part time, and employed full time, respectively]. In contrast to the findings for careeroriented women, the self-esteem of women who were not career oriented and who were employed full time was lower, although nonsignificantly, than for those employed part time or not at all (See Fig. 1).

\section{Life Satisfaction}

The findings for life satisfaction, as measured by the statement, "I think of my life today as interesting and satisfying," followed the same pattern as for self-esteem. Figure 2 presents the adjusted mean ratings by employment status and career orientation. Again, for career-oriented women, employment status was associated strongly with satisfaction $[F(2,724)=23.03$, $p<.00001$ (adjusted means, 3.74, 4.10, 4.38, for not employed, employed part time, and employed full time, respectively)]. Scheffé comparisons indicated that career-oriented women who were employed full time reported greater satisfaction than those employed part time $(p<.001)$ or not employed $(p<.00001)$. Career-oriented women employed part time also were more satisfied than those who were not employed $(p<.0004)$. In contrast, the satisfaction of women who were not career oriented was unrelated to employment 

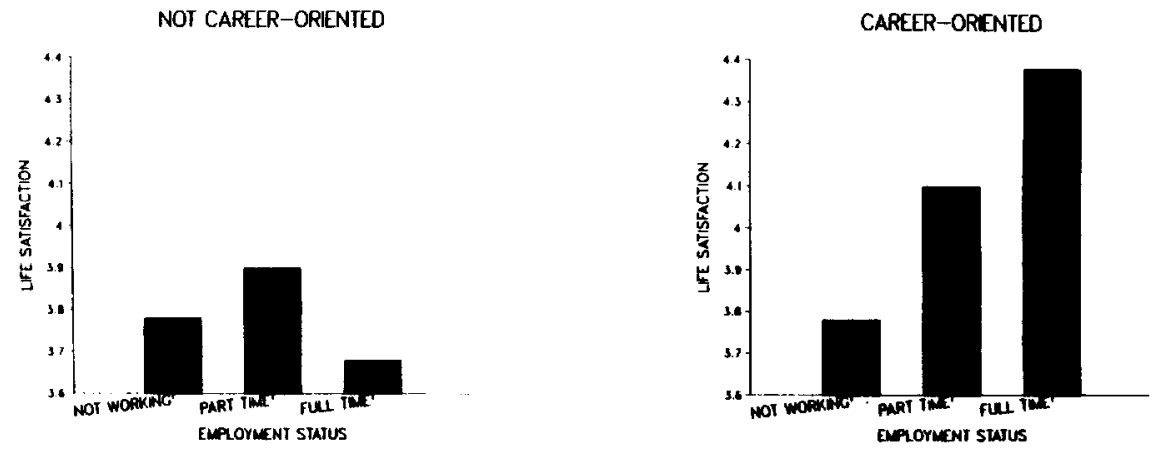

Fig. 2. Mean adjusted ratings of life satisfaction by career orientation and employment status.

status [ $F<1$ (adjusted means, 3.78, 3.90, 3.62, for not employed, employed part time, and employed full time, respectively)].

\section{Self-Descriptions}

The self-ratings for each of the 11 adjectives, some of which were very applicable to employment situations and some that were less so, provided some additional information about how employment and career perspective are related to women's thoughts about themselves. Table I indicates the proportion of career-oriented women and not career-oriented women who selected each adjective as very self-descriptive (a rating of 1 on the 5-point scale) for each level of employment status.

First, it is evident that career-oriented women were more likely than not career-oriented women to rate these adjectives as very self-descriptive. These differences were particularly apparent, however, for the job-related trait adjectives. Among career-oriented women, employment status was significantly associatetd with describing oneself as competitive occupationally $[F(2,648)=9.15, p<.0001]$, independent $[F(2,648)=3.49, p<.03]$, resourceful $[F(2,648)=3.27, p<.04]$, successful occupationally $[F(92,648)$ $=30.97, p<.00001]$, and marginally associated with ratings of intellectual $[F(2,648)=2.44, p<.09]$.

The Scheffé comparisons among levels of employment status revealed that women who were employed full time, relative to those employed part time or not employed, were significantly more likely $(p<.05$ or better for all comparisons) to describe themselves as very competitive occupationally, very resourceful, and very successful occupationally. Those employed full time also described themselves as very independent more often than those 
Table I. Mean Adjusted Proportion of Career-Oriented Women and Not Career-Oriented Women Endorsing Each Characteristic ${ }^{\alpha}$

\begin{tabular}{|c|c|c|c|c|c|c|}
\hline & \multicolumn{3}{|c|}{ Career oriented } & \multicolumn{3}{|c|}{ Not career-oriented } \\
\hline & $\begin{array}{c}\begin{array}{c}\text { Not } \\
\text { working }\end{array} \\
\end{array}$ & $\begin{array}{l}\text { Working } \\
\text { part-time }\end{array}$ & $\begin{array}{l}\text { Working } \\
\text { full-time }\end{array}$ & $\begin{array}{c}\begin{array}{c}\text { Not } \\
\text { working }\end{array} \\
\end{array}$ & $\begin{array}{l}\text { Working } \\
\text { part-time }\end{array}$ & $\begin{array}{l}\text { Working } \\
\text { full-time }\end{array}$ \\
\hline \multicolumn{7}{|l|}{$\begin{array}{l}\text { Work-related } \\
\text { characteristics }\end{array}$} \\
\hline $\begin{array}{l}\text { Competitive } \\
\text { occupationally }\end{array}$ & $.13_{a}$ & $.18_{a}$ & $.30_{b}$ & $-.01_{a}$ & $.02_{a}$ & $.19_{b}$ \\
\hline Independent & $.44_{a b}$ & $.40_{a}$ & $.52_{b}$ & .28 & .31 & .43 \\
\hline Intellectual & $.43_{\alpha}$ & $.38_{a b}$ & $.32_{b}$ & .25 & .11 & .17 \\
\hline Resourceful & $.50_{a}$ & $.50_{a}$ & $.61_{b}$ & .40 & .38 & .39 \\
\hline $\begin{array}{l}\text { Successful } \\
\text { academically }\end{array}$ & .55 & .50 & .51 & .32 & .24 & .25 \\
\hline $\begin{array}{l}\text { Successful } \\
\text { occupationally }\end{array}$ & $.14_{\alpha}$ & $.22_{a}$ & $.47 b$ & .10 & .15 & .22 \\
\hline \multicolumn{7}{|l|}{$\begin{array}{l}\text { Other } \\
\text { characteristics }\end{array}$} \\
\hline Attractive & .16 & .18 & .15 & .18 & .14 & .14 \\
\hline Conventional & .08 & .09 & .06 & .07 & .26 & .19 \\
\hline Creative & .33 & .35 & .35 & $.36_{a}$ & $.23_{a b}$ & $.04_{b}$ \\
\hline Nervous & .09 & .08 & .06 & $.00_{a}$ & $.08_{a b}$ & $.18_{b}$ \\
\hline Successful & & & & & & \\
\hline socially & .23 & .21 & .24 & .12 & .15 & .12 \\
\hline$n$ & 147 & 187 & 320 & 30 & 45 & 23 \\
\hline
\end{tabular}

${ }^{a}$ Scheffé comparisons of means within each career orientation group differed significantly at $p<.05$ or better for pairs with different subscripts.

employed part time $(p<.01)$, and marginally more often than women who were not employed $(p=.10)$. Only the adjective "intellectual" was endorsed more frequently by career-oriented women who were not employed, in contrast to those employed full time $(p<.03)$.

A somewhat different pattern emerges for women who are not career oriented. For these women, the adjectives for which endorsement differed by employment status were competitive occupationally $[F(2,92)=5.88, p$ $<.004]$, creative $[F(2,92)=3.60, p<.03]$, and nervous $[F(2,92)=2.73$, $p<.07]$. Women who were employed full time and who were not career oriented were somewhat more likely to define themselves as very nervous in contrast to women who were not employed $(p<.02)$, and as very competitive occupationally in contrast to those employed part time $(p<.005)$ or not employed $(p<.002)$. However, women who were employed full time were less likely to describe themselves as creative than both women who were not employed $(p<.009)$ and women who were employed part time $(p<.09)$. 


\section{DISCUSSION}

These results suggest that how women think about the role of paid work in their lives mediates the relationship between employment status and wellbeing. Employment was associated with enhanced self-esteem and life satisfaction only when it was regarded as a career or significant life work. For those women who did not think of the paid work role as a long-term life goal, employment was not linked to higher self-esteem or life satisfaction.

Another important factor in determining the relationship between paid work and well-being is level of employment. Thus, career-oriented women held more positive feelings about themselves and were more satisfied with their lives when they were employed full time than when they were employed part time or not employed. It appears then, that for the career-oriented women in this study, full time employment was the situation that most clearly satisfied their goals and expectations about the role of paid work in their lives. For women who were not career oriented, being employed, and especially being employed full time, was not construed as important for self-definition, and as a result, employment did not appear particularly beneficial for selfesteem or life satisfaction.

The significance of employment for self-definition is also reflected in the data on self-descriptions. Women who were career oriented and who were employed accentuated a variety of job-related qualities (e.g., independent, competitive occupationally) in their self-definitions. It may be that the employment situation gives these women the opportunity to observe these qualities in their own behavior and thus emphasize them in their self-views, and women who are career oriented may be especially prepared to interpret their actions as expressive of qualities valued in their jobs. Not surprisingly, the women who were not career oriented did not characterize themselves in terms of work-relevant qualities. With the exception of the adjective resourceful, most of these women did not find any of the work-related adjectives to be particularly descriptive. Furthermore, for women who were not career oriented, employment was found associated with using the negative self-descriptor "very nervous" while not being employed was associated with defining one's self as creative.

Because our sample consisted primarily of highly educated careeroriented women with higher than average family incomes, it will be important to determine whether these findings generalize to a more respresentative sample of women. In addition, with the cross-sectional data reported here, the question of causality arises. Employment may lead to greater wellbeing and self-esteem, but it is also possible that women who are happier and more self-confident are more likely to become employed. These data do not allow a test of these two alternatives and, to some extent, the relationship may be reciprocal. We did look, however, at women who shared the same cognitive perspective (i.e., who were career oriented or not career oriented), 
and these women are likely to be similar in many respects unrelated to their employment status. For each group, we found that level of employment was associated with at least some differences in self-perception or wellbeing. Given the initial similarity of these groups, it is likely that employment, in itself, contributed significantly to these effects.

In sum, these findings challenge those that suggest a simple relationship between employment and well-being. It is obvious that employment is not equally valued by all individuals, yet this has been overlooked up to this point. The positive consequences of employment that have been repeatedly identified in large-scale studies of women's employment are likely to obtain only for those who regard their paid work role as a significant source of selffulfillment.

\section{REFERENCES}

Bielby D. D., \& Bielby, W. T. Work Commitment, sex-role attitudes, and women's employment. American Sociological Review, 1984, 49, 234-247.

Burke, R. J., \& Weir, T. Relationships of wives' employment status to husband, wife and pair satisfaction and performance. Journal of Marriage and the Family, 1976, 38, 279-287.

Campbell, A., Converse, P. E., \& Rogers, W. L. The quality of American life: Perceptions, evaluations, and satisfactions. New York: Russell Sage, 1976.

Coleman, L. M., \& Antonucci, T. C. Impact of work on women at midlife. Development Psychology, 1983, 19, 290-294.

Dowd, M. (1983, December 4). Many women in poll value jobs as much as family life. The New York Times, pp. 1, 66.

Dubin, R. Industrial workers' worlds: A study of the "central life interests" of industrial workers. Social Problems, 1956, 3, 131-142.

Favor, C. A. Women and achievement orientation across the life-cycle. Unpublished doctoral dissertation, University of Michigan, 1979.

Feld, S. Feelings of adjustment. In F. I. Nye, \& L. W. Hoffman (Eds.), The employed mother in America. Chicago: Rand McNally, 1963.

Ferree, M. M. Working class jobs, housework and paid work as sources of satisfaction. Social Problems, 1976, 22, 431-441.

Gurin, P. Gender consciousness: The impact of status change. Unpublished manuscript, University of Michigan, 1984.

Kessler, R., \& McRae, J. A. The effect of wives' employment on the mental health of married men and women. American Sociological Review, 1982, 47, 216-227.

Manis, J. D., \& Markus, H. Combining families and careers: View from-and of -different points of the life cycle. Changing family, changing workplace: New research. Center for Continuing Education of Women, Ann Arbor, MI, 1980.

Markus, H. Work, women, and well-being: A cognitive approach. In D. G. McGuigan (Ed.), Women's lives: New theory, rsearch, and policy. Ann Arbor: University of Michigan, Center for Continuing Education of Women, 1980.

Rosenberg, M. Society and the adolescent self-image. Princeton, NJ: Princeton University Press, 1965.

Warr, P., \& Parry, G. Paid employment and women's psychological well-being. Psychological Bulletin, 1982, 91, 498-516.

Wright, J. D. Are working women really more satisfied? Evidence from several national surveys. Journal of Marriage and the Family, 1978, 40, 301-313.

U.S. Department of Labor. Perspectives on working women: A databook: Bureau of Labor Statistics, Bulletin 2080, October 1980. 